\title{
Psychosocial profile and psychiatric morbidity among Egyptian patients after living donor liver transplantation
}

\author{
Mahmoud El-Meteini ${ }^{1}$, Eman Shorub², Dalia Abdel Moneim Mahmoud ${ }^{2^{*}}$ (D), Hussein Elkholy², \\ Ahmed El-Missiry ${ }^{2}$ and Reem Hashim²
}

\begin{abstract}
Background: Living donor liver transplantation is an effective line of therapy for patients with end-stage liver disease. While there are various psychiatric complications that affect donors, only a few studies investigated such complications among Egyptian living donors.

Results: The study showed psychiatric morbidity in 15\% of donors, especially anxiety disorders and major depression. Donors had high mean scores on psychoticism, neuroticism, impulsivity, and extraversion subscales of the EPQ. Female gender, younger age group, low educational level, managerial work, being the sibs of the recipients, and obtaining high scores in the EPQ were found to be independent risk factors correlated with the development of psychiatric morbidity in liver donors.

Conclusion: The increased frequency of psychiatric morbidity among liver donors raises the need for thorough pre- and postoperative psychiatric assessment and monitoring. It is mandatory to investigate the donors' personality traits preoperatively to assess the decision-making process for donation and postoperatively to plan appropriate protective and treatment programs.
\end{abstract}

Keywords: Psychosocial profile, Psychiatric morbidity, Personality traits, Living donor liver transplantation

\section{Background}

Living donor liver transplantation [LDLT] is an effective treatment for end-stage liver failure and overcomes the scarcity of cadaveric organs and thus reduces waiting list mortality [1].

It has been significantly associated with increased recipient survival rates, yet there are still concerns about the morbidity and even mortality in donors as they join the procedure while being generally healthy without any prior significant medical problem $[2,3]$. Thus, it is paramount to ensure donors' safety and mental and psychological well-being [4].

The spectrum of complications experienced by donors in LDLT has been described in a number of publications; about $67 \%$ of donors develop postoperative

\footnotetext{
* Correspondence: dollycage@hotmail.com

${ }^{2}$ The Institute of Psychiatry, Department of Neuropsychiatry, Faculty of

Medicine, Ain Shams University, El Abbassia, Cairo 11675, Egypt

Full list of author information is available at the end of the article
}

complications, most of them are typical for a major abdominal surgery, including wound infection, blood transfusion, and re-operation [5]. Meanwhile, there are very few data describing the psychiatric complications in living liver donors. The main concerns of the transplantation team are the surgical complications occurring in the immediate postoperative period; however, psychiatric complications may occur a long time after surgery. During this phase of postoperative recovery, assessment of donors at most centers is very limited or non-existing. Therefore, there should be more of published reports on the frequency and nature of psychiatric complications in this group of donors [6,7].

In Egypt, living donor liver transplant has increased over the past few years as the only permissible type of transplant in the absence of a law that permits the use of deceased donor organs [8]. Nonetheless, the psychological aspects of the Egyptian living donor liver transplantation (as far as we know) have not been investigated. Thus, the 
aim of this study is to assess the psychiatric morbidity rate and risk factors encountered in the donor's post donation as well as their psychosocial profile and personality traits. This research is the third report of a series of publications in this field $[9,10]$.

\section{Materials and methods}

A prospective longitudinal study was conducted on donors referred from the Liver Transplantation Unit in Ain Shams University Specialized Hospitals, Wadi El-Nil Hospital, and Egypt Air Hospital. They are located in Cairo and serve both urban and rural areas, including greater Cairo and other governorates. The study protocol was approved by the Ethical Committees of the three mentioned hospitals. A written informed consent was obtained from all respondents.

The study included all potential donors [11] over a 1year period, both male and female with an age range from 18 to 45 years old, which is the age limit for living liver donation. A total of 65 participants were assessed. However, 31 were excluded (11 recipients died before surgery and their donors were dismissed; 5 were excluded because of a history of substance abuse, bipolar disorder, and panic disorder; 4 were hesitant about donation; 2 declined when they knew that the recipient chance for recovery was questionable; 4 were subjected to coercion by their families putting pressure on them to donate; 4 left hospital on the night of the surgery after canceling their consent to donate without giving any reasons; and 1 donor refused to sign the consent). Thus, the current study included 33 actual donors [11] who were subjected to the following:

- A preliminary interview using a designed sheet for obtaining the following: age, gender, educational level, employment status, marital status, relation to the recipient, satisfaction about donation, and willingness to donate.

- The General Health Questionnaire-28 (GHQ-28) [12]: It was initially developed as a first-stage screening instrument for psychiatric illness in order to identify potential cases, which could then be verified and the nature of which could be determined by using second-stage instrument as clinical interview schedule. The version used in this study is the Arabic version, with a cut-off point 7 in the Egyptian community [13, 14]. We used this questionnaire prior to recruitment for surgery to exclude for minor psychiatric morbidity; then, we used it 3 months postoperatively to detect the emergence of such morbidities.

- The Structured Clinical Interview for DSM-IV (SCID-I) [15]: It is a semi-structured diagnostic clinical interview for DSM-IV comprising seven modules, focused on mood, psychotic, substance abuse, anxiety, somatoform, eating, and adjustment disorders. It is considered the standard interview to verify the diagnosis in clinical trials and is extensively used in other forms of psychiatric research. In this study, we used the Arabic Translated Version [16]. We used the SCID-I test twice: first in the early recruitment phase on all potential donors and those who had any psychiatric diagnosis were excluded. Then, it was reapplied 3 months after donation on all actual donors to evaluate any current psychiatric disorders.

- The Eysenck Personality Questionnaire (E.P.Q.) [17]: It is a simple self-report test, consisting of 101 questions designed to measure two major dimensions of personality: psychoticism $(\mathrm{P})$, which is related to odd cruel, antisocial behavior, suspicion, and a lack of feeling; neuroticism $(\mathrm{N})$, which is defined as emotional liability, over responsiveness, and liability to neurotic breakdown under stress; and extraversion-introversion (E/I), which implies the presence of an outgoing personality with uninhibited social tendencies. We used the Arabic version [18].

-The D-scale of Guilford Inventory of Personality Factors [19]: The D-scale is one of the dimensions of the Guilford Inventory representing depressive tendencies. This scale includes a cluster of factors, for example, fluctuation of mood, optimism, pessimism, day dreaming, excitability, and feeling of guilt, worry, loneliness, and ill health. It consists of 59 questions to be answered with yes or no. We used the Arabic version with a score range of $27 \pm 10$ as the norms of the Egyptian population [20].

\section{Statistical analysis}

The data were tabulated and statistically analyzed using the Statistical Package for Social Sciences software (SPSS; version 17) [21]. Continuous variables were presented as mean \pm SD and categorical variables as absolute numbers (percentages). Categorical variables were compared by chi-square test. The logistic regression backward likelihood ratio technique was used to find out the significant independent predictors of psychiatric morbidity. A $P$ value of 0.05 or less was considered significant, and a $P$ value of 0.01 or less was considered highly significant.

\section{Results}

\section{Socio-demographic characteristics of donors}

The age range of the sample was $18-45$ with a mean of $30.3 \pm 7.12$ years. The majority of the sample was males $23(69.7 \%)$ with 10 females (30.3\%). Twenty out of the 33 donors $(60.6 \%)$ were married; most of them were living in a stable relationship. Twenty subjects $(60.5 \%)$ received school education (primary, preparatory, secondary, and technical schools), 4 (9\%) were illiterate (assisted during the interviews in performing the assessments), and 10 $(30.3 \%)$ were university graduates. Meanwhile, $66.7 \%$ of donors were employed, $27.3 \%$ were manual workers, $24.2 \%$ were employees, and $15.2 \%$ were working in managerial jobs, while $21.2 \%$ were housewives and $12 \%$ were students (Table 1). 
Table 1 Socio-demographic data of the donors

\begin{tabular}{|c|c|c|c|}
\hline & Variable & $n=33$ & Percentage \\
\hline Age & Mean \pm SD $(30.33 \pm 7.127)$ & & \\
\hline \multirow[t]{2}{*}{ Gender } & Male & 23 & $69.7 \%$ \\
\hline & Female & 10 & $30.3 \%$ \\
\hline \multirow[t]{6}{*}{ Education } & Illiterate & 3 & $9.1 \%$ \\
\hline & Primary school & 4 & $12.1 \%$ \\
\hline & Preparatory school & 1 & $3 \%$ \\
\hline & Secondary school & 1 & $3 \%$ \\
\hline & Technical & 14 & $42.4 \%$ \\
\hline & University & 10 & $30.3 \%$ \\
\hline \multirow[t]{5}{*}{ Occupation } & Manual workers & 9 & $27.3 \%$ \\
\hline & Employees & 8 & $24.2 \%$ \\
\hline & Managerial & 5 & $15.2 \%$ \\
\hline & House wives & 7 & $21.2 \%$ \\
\hline & Student & 4 & $12.1 \%$ \\
\hline \multirow[t]{2}{*}{ Marital status } & Married & 20 & $60.6 \%$ \\
\hline & Non-married & 13 & $39.4 \%$ \\
\hline
\end{tabular}

\section{Relationship of donors to recipients}

Around $42.4 \%$ of donors were volunteers not related to the recipients. Whereas $21.2 \%$ donated to their fathers, $3 \%$ donated to their mothers, $12.1 \%$ to their sibs, $12.1 \%$ to other relatives, and $9.10 \%$ donated to their maternal uncles (Fig. 1).

\section{Postoperative surgical complications in donors}

Three months post donation, the majority (94\%) reported grade 1 complication and $3 \%$ had grade 2 , while another 3\% showed grade 3a complications according to the Clavien Classification [22].

\section{Satisfaction with the decision to donate and willingness to donate again}

The majority of the donors around 67\% $(n=22)$ reported that they would not donate again, whereas $33 \%$ ( $n=11$ ) were willing to re-donate. It is worth telling that some of the donors who refused to donate again lost their recipients, while others had developed surgical

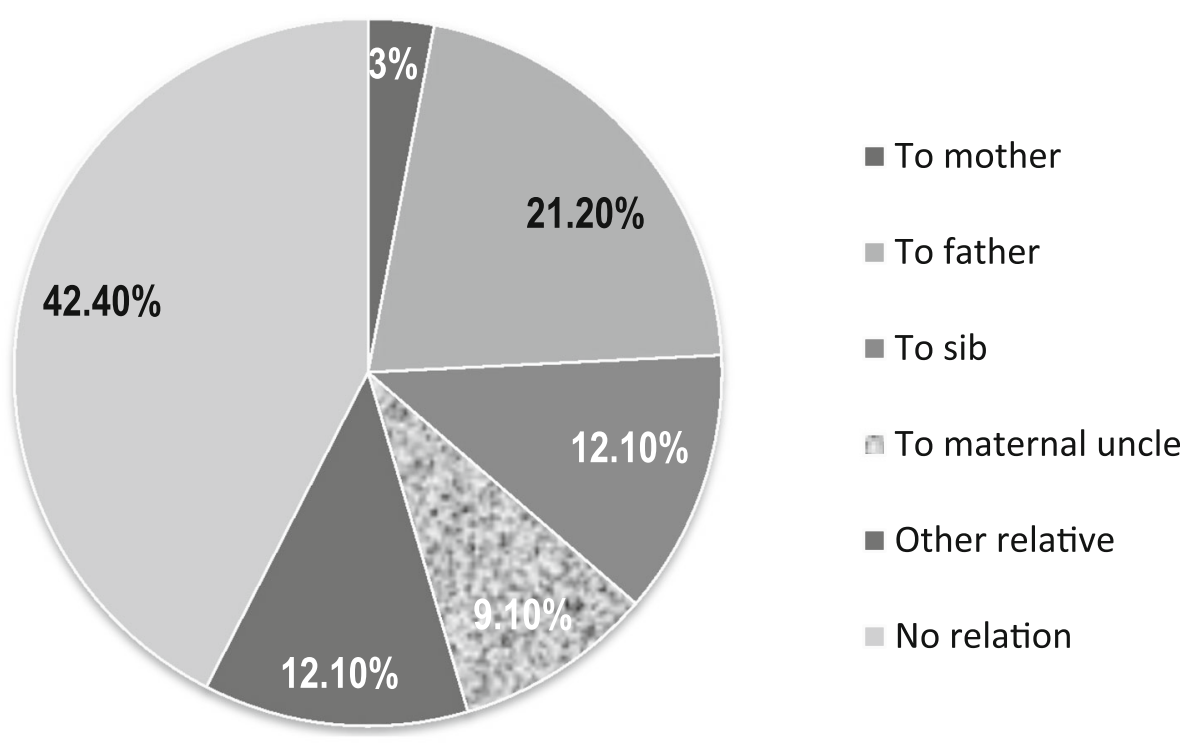

Fig. 1 The relation of donors to the recipients 
complications or experienced greater pain post donation than they had anticipated. It is worth telling that $73 \%$ of the recipients $(n=24)$ were still alive 3 months after donation, while the rest unfortunately died.

\section{Assessment of personality traits}

Data in Table 2 revealed that the mean scores of donors on Eysenck Personality Questionnaire for psychoticism (P) subscale $(5.4 \pm 2.7)$ were higher than the norms of the Egyptian population; this may indicate that they had a tendency to tough-mindedness, recklessness, hostility, anger, and impulsiveness. Donors scored higher than the Egyptian population norms on neuroticism $(\mathrm{N})$ subscale $(10.1 \pm 4.4)$ which implies that they had low activation thresholds and inability to inhibit or control their emotional reactions, experienced negative effect in the face of very minor stressors, and may have high levels of negative effect such as depression and anxiety. Moreover, donors showed higher scores on impulsivity (11.48 \pm 5.29$)$ and also on extraversion (E) (13.36 \pm 4.6) subscales compared to the normal Egyptian population which means that they were good mixers, sociable, and impulsive and have a tendency to become aggressive.

Furthermore, Table 2 showed that the majority of donors assessed by the D-scale of Guilford Inventory of Personality Factors had scores $(24.1 \pm 12.8)$ that were within the norms of the Egyptian scores.

\section{Psychiatric morbidity 3 months after donation}

Fifteen percent of donors scored above 7 in the General Health Questionnaire-28 3 months after donation. They were diagnosed according to the DSM-IV with major depression (of moderate severity) $(n=2,6 \%)$, anxiety disorders $(n=2,6 \%)$, and adjustment disorder with mixed anxiety and depression $(n=1,3 \%)$. None of the donors had severe depression, bipolar disorder, or any other psychiatric morbidity (Table 3 ).

\section{Risk factors associated with psychiatric morbidity post donation (Table 4)}

To evaluate the predictive value of the previously analyzed factors, we performed linear regression analysis test. Results revealed that risk factors for psychiatric morbidity were young age group $(P=0.012)$, female gender $(P=0.07)$,

Table 2 Personality traits using the EPQ and D-scale of Guilford inventory

\begin{tabular}{lll}
\hline Personality assessment & Mean \pm SD & $\begin{array}{l}\text { Norms of Egyptian } \\
\text { population }\end{array}$ \\
\hline EPQ Psychoticism & $5.48 \pm 2.70$ & $2 \pm 2$ \\
EPQ Neuroticism & $10.15 \pm 4.49$ & $9 \pm 5$ \\
EPQ Impulsivity & $11.48 \pm 5.3$ & $9 \pm 4$ \\
EPQ Extroversion & $13.4 \pm 4.60$ & $12 \pm 4$ \\
Guilford inventory (D) & $24.1 \pm 12.81$ & $27 \pm 10$ \\
\hline
\end{tabular}

Table 3 Psychiatric morbidity three months post-donation by SCID-I

\begin{tabular}{lll}
\hline SCID-I & $\operatorname{LDLT}(N=33)$ \\
\hline Psychiatric disorders & Anxiety disorder & $2(6 \%)$ \\
& Major depressive episode & $2(6 \%)$ \\
& $\begin{array}{l}\text { Adjustment disorder with mixed } \\
\text { anxiety \& depression }\end{array}$ & $1(3 \%)$ \\
&
\end{tabular}

No Psychiatric disorders $28(85 \%)$

receiving secondary education $(P=0.041)$, working in managerial jobs $(P=0.019)$ or being students $(P=0.003)$, being the sibs of the recipients, and obtaining higher scores in EPQ psychoticism $(P=0.049)$, neuroticism $(P=0.000)$, and extraversion and impulsivity $(P=0.000)$.

\section{Discussion}

Living donor liver transplantation is an alternative for patients in need for liver transplantation who are not likely to receive a cadaveric donor for liver transplant in a timely manner. There are a few studies, which evaluated both the preoperative and postoperative psychological statuses of liver donors [11]. Consequently, our study aimed to evaluate the psychiatric morbidity and the associated risk factors in a sample of Egyptian liver donors preoperatively and 3-months post donation.

\section{Psycho-demographic characteristics of Egyptian living donor liver transplantation}

Our demographic information of donors was approximately similar to those reported in previous studies [23, 24, 25]. However, there were some differences as regards the donor's gender as the majority of the actual donors in our study were males $(69.7 \%)$ compared to $(30.3 \%)$ females. This gender disparity was non-congruent with a previous study in which women had a higher motivation and readiness for life organ donation [11]. In a study done by Chan and his colleagues [26], the actual donors in their series were females and most of them were wives of the recipients.

Donation patterns had consistently showed a greater number of women as living donors than men, especially in most of the western countries. Herman and his colleagues [27] found that there were more male than female donors in eight countries (Japan, Korea, Egypt, Saudi Arabia, Spain, Turkey, Germany, and the USA), with a proportion higher than $70 \%$ of male donors was observed in three countries only (Egypt, Saudi Arabia, and Korea).

Two thirds of our donors were married, which may reflect the degree of social support provided by family members. We were in agreement with Erim and his coworkers [11] who found that when family members in Germany were involved and gave all possible support to donors, the mean values of anxiety and depression were much reduced. 
Table 4 Risk factors correlated with psychiatric morbidity

\begin{tabular}{|c|c|c|c|c|c|c|}
\hline & Model & Unstanda & Coefficients & Standardized Coefficients & $\mathrm{t}$ & Sig. \\
\hline & & $\bar{B}$ & Std. Error & Beta & & \\
\hline Age & Donor's Age & -.101 & .023 & -.072 & -4.337 & $.012^{*}$ \\
\hline Gender & Female donors & 5.045 & 1.291 & .417 & 3.907 & $.017^{*}$ \\
\hline Marital status & Marital status & -1.208 & .844 & -.136 & -1.431 & .226 \\
\hline Education & Primary education & -2.187 & 3.320 & -.128 & -.659 & .546 \\
\hline & Preparatory education & -2.896 & 3.443 & -.089 & -.841 & .448 \\
\hline & Secondary schools & -11.848 & 3.973 & -.365 & -2.982 & $.041^{*}$ \\
\hline & Technical schools & 1.281 & 3.280 & .114 & .390 & .716 \\
\hline & University & 2.406 & .787 & .112 & 3.056 & $.038^{*}$ \\
\hline Occupation & Employee & -.421 & 1.079 & -.032 & -.390 & .716 \\
\hline & Managerial & -3.140 & .830 & -.203 & -3.783 & $.019^{*}$ \\
\hline & Student & -11.460 & 1.710 & -.673 & -6.701 & $.003^{*}$ \\
\hline Relation & Relation to recipient father & -3.830 & 2.369 & -.225 & -1.616 & .181 \\
\hline & Relation to recipient sibs & -13.253 & 2.409 & -.685 & -5.501 & $.005^{*}$ \\
\hline & Relation to recipient maternal uncle & -2.622 & 1.982 & -.154 & -1.323 & .256 \\
\hline & No relation to recipient & -4.131 & 1.490 & -.367 & -2.772 & $.050^{*}$ \\
\hline Personality traits & Guilford inventory & .135 & .084 & .306 & 1.611 & .182 \\
\hline & EPQ Psychoticism & 1.038 & .371 & .497 & 2.797 & $.049^{*}$ \\
\hline & EPQ Neuroticism & -2.077 & .103 & -.930 & -20.095 & $.000^{*}$ \\
\hline & EPQ impulsivity & 1.814 & .129 & .959 & 14.016 & $.000^{*}$ \\
\hline & EPQ Extra version & 1.352 & .036 & 622 & 37.533 & $.000^{*}$ \\
\hline
\end{tabular}

(*): Significant

In the current study, a considerable percentage (42.4\%) received technical education and (30.3\%) were university graduates, $(9 \%)$ were illiterate, and the rest received different types of non-university education. We believed that educational level can affect the degree to which the donors grasp and understand the information given to them about surgical details and this could allow them to communicate their decision better with the transplant team.

\section{Relation of donors to recipients}

The reported dynamic factors underlying a donor's motivation included the social environment, the relationship to the recipient, and the donor's personal attitude and benefits [28]. Many donors are blood-related to the recipients. This was already assumed because those donors have close emotional ties to the recipients, and the matching of the genetic materials is often successful [27].

Surprisingly, in our research, $42.2 \%$ of the actual donors were volunteers who had no close or remote relation to the recipients; unfortunately, we did not study thoroughly their motivation to donate; thus, we were not able to clarify the reasons for their altruistic attitudes. Moreover, in some western communities, a considerable percentage of donors were not blood-related [27].
In an Egyptian study [8], it was stated that donation of the non-relative recipient is a complex procedure. It identified donors who justified their will to donate by their religious beliefs. Informed consent is very important, and ethically speaking, it is necessary to exclude financial inducement before donation, as the primary selection criterion for a living liver donor should be volunteerism not being vendor donors.

Spouses are the most common "voluntary living donors" for adult recipients in Europe and Asian [27, 29, 30]. Surprisingly, none of our recipients received the donation from their spouses. This point will need further studying from a cultural perspective. In our study, those who donated to their fathers were $21.2 \%$, their mothers $3 \%$, and sibs $12.1 \%$. The motivation behind this donation is simply understood by their strong emotional relation and bonding to their family members and their wish to keep their beloved ones alive. We are in agreement with previous authors who ascribed donation to parents as a way to express love and gratitude, for whom it is considered a salvation step to relieve them from suffering [8].

\section{Satisfaction with the decision to donate}

Findings related to the satisfaction with the decision to donate and willingness to donate again were different; in 
some centers, the majority of donors confirmed that they would consent to donate once more [25, 31]. In this current study, on asking about the possibility of donating again, $33 \%$ of actual donors were willing to donate again yet the majority (67\%) reported that they were not willing to due to their experiences of losing their recipients or feeling traumatized shortly after surgery.

Contrary to our findings, previous researchers reported that all donors in their samples would willingly donate again, as they believed they had benefited from the donation, whereas others reported that most of the donors (73.8\%) would donate again, $19.2 \%$ would not, and $7 \%$ did not answer this question [25, 32].

\section{Personality traits of donors}

The assessment of personality traits is an essential step in the donation procedure; it may be helpful in explaining whether the donor might be inherently more prone to a psychological sequel or whether the stress of the operation increases the risk of such complications.

Our findings indicate that the personality trait assessment may be helpful to provide necessary psychological support to help donors cope appropriately with the postsurgical stressful situation. Supporting this view, various studies [29, 33, 34] emphasized the importance of assessing the personality of the potential donors prior to the individual's decision-making to donate; some potential donors with high trait anxiety tended to decide to donate in a "postponement" pattern than a "deliberate" pattern.

In our study, we found that the actual donors did not score higher in D-score of Guilford's battery, which means that they had no trait depression or inherited susceptibility to depression. On the other hand, our data on personality traits of donors using the EPQ revealed that their mean scores in the EPQ, psychoticism, and impulsivity were higher than those of the published Egyptian norms, which may indicate that they had tendencies to experience negative effect on facing stress. Their impulsivity may reflect that the donation process for them is a personal challenge and an opportunity for an exceptional experience or to initiate life change. Their high scores on neuroticism may reflect their vulnerability to anxiety as was extensively explained by Eysenck and Eysenck [17].

\section{Psychiatric morbidity among Egyptian living donor liver transplantation}

There are few data describing long-term psychiatric complications in living liver donor post donation [25]. The infrequent recording of such problems was explained by the absence of careful donor monitoring during long-term follow-up visits.

On the contrary, some studies reported that liver donors reached improved mental well-being in the long-term follow-up period $[7,26,35,36]$. Other findings reported that donors had an increased rate of psychiatric complications, including depression, anxiety, bipolar disorder, and substance abuse [11].

In the current study using SCID-I for diagnosis of psychiatric disorders according to DSM-IV criteria, 3 months after donation revealed that 15\% of the Egyptian actual donors had an Axis-I diagnosis. Our results were consistent with previous findings, which found that the occurrence of post donation depression rates ranged between 0.2 and 15\% among donors [37]. Moreover, Gokce and coworkers [32] found that $12.5 \%$ of donors had low mood and $6.3 \%$ were in need for pharmacological and psychotherapeutic interventions. Other studies showed a lower prevalence reported in Germany (9.3\%) [11] and Japan (9.7\%) [38]. Different results could be attributed to the socio-cultural quality of living confounding factors and the difference in sampling and methods of assessment.

In our research, major depression and anxiety disorders were by far the commonest diagnostic categories encountered being $6 \%$ and $6 \%$ respectively. A higher rate of major depression was reported in Japan by Kizilisik and colleagues [39] who found a rate of $7.1 \%$ for major depression post donation. However, only one of those donors received antidepressants.

On the other hand, a lower rate of clinical depression was recorded by other investigators with a range from only 3 to $4.9 \%$ [24, 38]. These discrepancies may reflect cultural and methodological differences.

Depression reported in donors may reflect their feeling of loss of capacity, helplessness, loss of function, and inability to cope. Anxiety may be due to the fear and threat of the loss of a beloved person. We are in agreement with a previous Egyptian study which considered that the donation is an attempt to become like the recipient by undergoing a similar serious operation [8].

In the current study, the severity of anxiety and depression was generally mild, which necessitates minor psychotherapeutic and pharmacological intervention. It seems mandatory to follow those donors for a longer time after they return successfully back to normal life and to decide whether their symptoms will persist or not.

On elucidating the predictive risk factors associated with psychiatric morbidity in our study, we found that being a female was a risk for developing psychiatric disorders. This notion agrees with various studies' findings $[11,36,40]$. It could be explained by their genderrelated anxiety and heightened stress upon their responsibilities towards their homes.

In our study, young donors were more prone to develop psychiatric morbidity. Similarly, previous studies found that donors under the age of 55 were subjected to more health-related stressors, while donors aged from 55 to 60 years of age were found to have significantly better mental health [29]. 
Having secondary educational level was statistically significantly correlated with psychological symptoms in both univariate and linear regression analyses in our research. This is similar to results of a study by Erim and colleagues [11]. This may be attributed to the fact that persons with low educational level were less confident, and they could not handle the physical, mental, and financial burdens of organ transplantation.

Regarding personality traits of donors, we found that having high scores in psychoticism, neuroticism, and impulsivity was correlated with the development of psychiatric morbidity, which was statistically significant in both univariate and linear regression analysis. Nevertheless, extraversion proved to be highly significant on using linear regression analysis. Other studies showed that low extraversion scores were linked to emotional distress and anxiety; specifically social phobia [23, 41].

It is worth mentioning that individuals with high neuroticism had low activation thresholds, were unable to inhibit or control their emotional reactions, and experienced negative effect in the face of minor stressors; hence they were more liable to anxiety under stress. On the other hand, those with high psychoticism had tough-mindedness, suspiciousness, recklessness, hostility, anger, and impulsiveness that made them more prone to develop psychiatric illness [24]. Moreover, donors who scored high in impulsivity automatically responded to donate to save their loved ones' lives, and this might be conflicting with their family fears and work responsibilities, which caused additional stress on them that increased their tendency to experience psychological symptoms.

\section{Conclusion}

The study showed that 15\% of living donors developed psychiatric morbidity 3-months post donation; also there are a number of psycho-demographic and personality traits. Risk factors were associated with this psychiatric morbidity. The increased frequency of psychiatric problems among the living liver donors raises the need for a long-term careful postoperative psychiatric assessment and monitoring. It seems mandatory to investigate the donors' personality traits preoperative to assess the decisionmaking process and to plan for appropriate past operative psychological support.

\section{Abbreviations \\ DSM-IV: Diagnostic and Statistical Manual of Mental Disorders, 4th Edition; EPQ: Eysenck Personality Questionnaire; GHQ: General Health Questionnaire; LDLT: Living donor liver transplantation; SCID I: The Structured Clinical Interview for DSM-IV Axis I Disorders (SCID-I); SPSS: Statistical Package for Social Sciences}

\section{Acknowledgements}

The authors would like to thank Professor Afaf Hamed Khalil, Professor Abdel Nasser Omar, Professor Eman Abo El Ela, and Dr. Marwa Abdel Maguid, from the Institute of Psychiatry, Ain Shams University, Egypt, for their great help and support. We cordially thank all the participants who accepted to share in this study.

Strength and limitations

This study is one of the preliminary researches in Egypt that was interested in exploring the psychiatric morbidity and associated demographic and personality risk factors among living liver donors after transplantation. However, the study was limited by the small sample size; hence, its results could not be generalized.

\section{Authors' contributions}

MEM chose the topic, put the plan of methodology, and supervised the data collection. ES shared in the paper manuscript writing. DAMM contributed to the paper submission in the journal (corresponding author) and shared in the paper manuscript writing. HE shared in the paper manuscript writing. AEM shared in the paper manuscript writing and supervising of the field work. $\mathrm{RH}$ contributed to the data collection and implemented the field work regarding the psychiatric interviews with the patients. All authors read and approved the final manuscript

\section{Funding}

No funding was provided

\section{Availability of data and materials}

The authors confirm that the data supporting the findings of this study are available within the article and/or its supplementary materials.

\section{Ethics approval and consent to participate}

The research was approved by Ain Shams University Faculty of Medicine Ethical Committee of Scientific Research.

A written informed consent was obtained from all respondents.

Each patient included in this study was notified personally about the nature and aim of the study and about keeping all the medical data presented by the patient confidential and restricted to the study purpose only and that the patient has free will not to share in the study or withdraw at any time without affecting the medical service he is provided with and that the work may be published without mentioning his identity.

Consent for publication

Not applicable

\section{Competing interests}

The authors declare that they have no competing interests.

\section{Author details}

${ }^{1}$ Liver Transplant Unit, General Surgery department, Faculty of Medicine, Ain Shams University, Cairo, Egypt. ${ }^{2}$ The Institute of Psychiatry, Department of Neuropsychiatry, Faculty of Medicine, Ain Shams University, El Abbassia, Cairo 11675, Egypt.

Received: 26 June 2019 Accepted: 31 July 2019

Published online: 05 September 2019

\section{References}

1. Shah SA, Levy GA, Greig PD, Smith R, McGilvray ID, Lilly LB et al (2007) Reduced mortality with right-lobe living donor compared to deceaseddonor liver transplantation when analyzed from the time of listing. Am. J. Transplant. 7:998-1002

2. Krahn L, DiMartini A (2005) Psychiatric and psychosocial aspects of liver transplantation. Liver Transpl. 11:1157-1168

3. Heinrich TW, Marcangelo M (2009) Psychiatric issues in solid organ transplantation. Harv. Rev. Psychiatry 17(6):398-406

4. Abdullah K, Abdeldayem H, Salama IA, Badah K, Al-Somali B, Abdulkareem A (2007) Retrospective analysis of the causes of rejection of potential donors for living related liver transplantation. Hepatol. Int. 1:431-436

5. Bowers K, Sandler R, Shrestha R (2002) Donor morbidity associated with right lobectomy for living donor liver transplantation to adult recipients: a systematic review. Liver Transpl. 8:110-117

6. Intaraprasong P, Sobhonslidsuk A, Tongprasert S (2010) Donor outcomes after living donor liver transplantation (LDLT). J. Med. Assoc. Thai. 93(11): 1340-1343 
7. Dew MA, AF DM, Ladner DP, Simpson MA, Pomfret EA, Gillespie BW et al (2016) Psychosocial outcomes 3 to 10 years after donation in the adult to adult living donor liver transplantation cohort study. Transplantation 100(6):1257-1269

8. Abdeldayem H, Allam N, Salah E, Aziz A, Kashkoush S, Adawy N et al (2009) Moral and ethical issues in living-donor liver transplant in Egypt. Exp. Clin. Transplant. 7(1):18-24

9. El Meteini MS, Hamed MA, Awaad MI, El Missiry AA, El Missiry MA, Hashem RE (2014) Factors correlated with the emergence of depressive symptoms in Egyptian donors after living donor liver transplantation. Middle East Current Psychiatry 21(2):113-120

10. Omar AM, El Meteini MS, Abo El Ela El, Elbatrawy AN, Sabry WM, Hashem RE (2015) Change in the donors' quality of life after living-donor liver transplantation surgery: a prospective longitudinal study. Middle East Current Psychiatry 22:143-151

11. Erim Y, Beckmann M, Valentin-Gamazo C, Malago M, Frilling A, Schlaak JF et al (2006) Quality of life and psychiatric complications after adult living donor liver transplantation. Liver Transpl. 12:1782-1790

12. Goldberg DP, Hillier VF (1979) A scaled version of the General Health Questionnaire. Psychol. Med. 9:139-145

13. Okasha A (1988) Okasha's clinical psychiatry (Arabic version of General Health Questionnaire). Anglo Egyptian Bookshop, Cairo

14. Abd EL Hakeem R (1988) Prevalence of depressive disorders in a sample of rural and urban Egyptian communities [MSc thesis]. Faculty of Medicine, Ain Shams University, Egypt

15. First M, Spitzer R, Williams J, Gibbon M, Janet BW (1995) Structured Clinical Interview for DSM-IV (SCID-I) (user's guide and interview) research version. Biometrics Research Department, New York Psychiatric Institute, New York

16. El Missiry A Homicide and psychiatric illness, an Egyptian study (MD thesis Cairo. Faculty of Medicine, Ain Shams University; 2003.

17. Eysenck HJ, Eysenck SBG Manual of the Eysenck Personality Questionnaire (adult and junior) 1975. Hodder and Stoughton, London

18. Abdel Rahman M (2000) The Eysenck Personality Questionnaire. Anglo Egyptian Library, Cairo

19. Guillford JP, Zimmerman WS (1949) The Guilford-Zimmerman temperament survey: manual of instructions and interpretations. Sheridan Supply Co, Beverly Hills, CA

20. Swaif M, Farghaly M (1979) The Guilford-Zimmerman temperament survey. Anglo Egyptian Library, Cairo

21. SPSS Inc. Released (2008) SPSS statistics for Windows, version 17.0. SPSS Inc, Chicago

22. Clavien P, Sanabria J, Strasberg S (1992) Proposed classification of complication of surgery with examples of utility in cholecystectomy. Surgery. 111:518-526

23. Karliova M, Malago' M, Valentin-Gamazo C, Reimer J, Treichel U, Franke GH et al (2002) Living-related liver transplantation from the view of the donor: a 1-year follow-up survey. Transplantation 73:1799

24. Verbesey JE, Simpson MA, Pomposelli JJ, Richman E, Bracken AM, Garrigan K et al (2005) Living donor adult liver transplantation: a longitudinal study of the donor's quality of life. Am. J. Transpl. 5(11):2770-2777

25. Trotter JF, Hill-Callahan MM, Gillespie BW, Nielsen CA, Saab S, Shrestha R et al (2007) Severe psychiatric problems in right hepatic lobe donors for living donor liver transplantation. Transplantation 83:1506-1508

26. Chan SC, Liu CL, Lo CM, Lam BK, Lee EW, Fan ST (2006) Donor quality of life before and after adult-to-adult right liver live donor liver transplantation. Liver Transpl. 12:1529-1536

27. Hermann HC, Klapp BF, Danzer G, Papachristou C (2010) Gender-specific differences associated with living donor liver transplantation: a review study. Liver Transpl. 16(3):375-386

28. Pacheco-Moreira L, Enne M, Balbi E, Halpern M, Peixoto A, Cerqueira A et al (2006) Selection of donors for living donor liver transplantation in a single center of a developing country: lessons learned from the first 100 cases. Pediatr Transplant. 10:311-315

29. Walter M, Pascher A, Papachristou C, Danzer G, Langrehr M, Frommer J et al (2005) Psychological and somatic aspects of living donor liver transplantation: preoperative assessment and outcome of donors. DMW 130:1749-1755

30. Noma S, Hayashi A, Uehara M, Uemoto S, Murai T (2011) Comparison between psychosocial long-term outcome of recipients and donors after adult-to-adult living donor liver transplantation. Clin. Transplan. 25:714-720

31. Kim-Schluger L, Florman SS, Schiano T, O'Rourke M, Gagliardi R, Drooker M, et al. Quality of life after lobectomy for adult liver transplantation. Transplantation 2002; 73: 1593.
32. Gokce S, Durmaz O, Peykerl Gursu G, Aydogan A, Celtik C, Ozden G et al (2011) Assessment of living donors with respect to pre- and posttransplant psychosocial properties and posttransplant family functioning in pediatric liver transplantation. Turk. J. Gastroenterol. 22(1):36-41

33. Uehara M, Hayashi A, Murai T, Noma S (2011) Psychological factors influencing donors' decision-making pattern in living-donor liver transplantation. Transplantation 92:936-942

34. Hayashi A, Noma S, Uehara M, Kuwabara H, Tanaka S, Furuno Y, et al. Relevant factors to psychological status of donors before living-related liver transplantation. Transplantation 2007; 84(10): 1255-61.

35. Schulz K, Hofmann C, Sander K, Burdelsi M, Rogiers X (2001) Comparison of quality of life and family stress in families of children with living-related liver transplants versus families of children who received a cadaveric liver. Transpl. Proc. 33(1-2):1496-1497

36. Jin S-G, Xiang B, Yan L-N, Chen Z-Y, Yang J-Y, Xu M-Q et al (2012) Quality of life and psychological outcome of donors after living donor liver transplantation. World J. Gastroenterol. 18:182-187

37. Middleton PF, Duffield M, Lynch SV, Padbury RTA, House T, Stanton P et al (2006) Living donor liver transplantation - adult donor outcomes: a systematic review. Liver Transpl. 12:24-30

38. Fukunishi I, Sugawara Y, Takayama T, Makuuchi M, Kawarasaki H, Surman OS (2002) Association between pretransplant psychological assessments and posttransplant psychiatric disorders in living-related transplantation. Psychosomatics 43:49-54

39. Kizilisik AT, Shokouh-Amiri MH, Tombazzi CR, Desmukh S, Grewal HP, Vera SR et al (2001) Psychiatric complications after liver transplantation. Transplant. Proc. 33(7-8):3697

40. Banihashemi M, Hafezi M, Nasiri-Toosi M, Jafarian A, Reza Abbasi M, Arbabi $M$, et al. Psychosocial status of liver transplant candidates in Iran and its correlation with health-related quality of life and depression and anxiety. Journal of Transplantation, vol. 2015, Article ID 329615, 7 pages, 2015.

41. Valentin-Gamazo C, Malago M, Lutz JT KM, Frilling A, Nadalin S et al (2004) Experience after the evaluation of 700 potential donors for living donor liver transplantation in a single center. Liver Transpl. 10:1087-1096

\section{Publisher's Note}

Springer Nature remains neutral with regard to jurisdictional claims in published maps and institutional affiliations.

\section{Submit your manuscript to a SpringerOpen ${ }^{\circ}$ journal and benefit from:}

- Convenient online submission

- Rigorous peer review

- Open access: articles freely available online

High visibility within the field

- Retaining the copyright to your article

Submit your next manuscript at $>$ springeropen.com 